\title{
Report of the 14th International Symposium on Geo-Disaster Reduction on 10-13 October 2016 in Chengdu, China
}

\author{
Hufeng Yang ${ }^{1}$, Qiangong Cheng ${ }^{1 *}$ and Fawu Wang ${ }^{2}$
}

\begin{abstract}
The 14th International Symposium on Geo-disaster Reduction (ISGdR) was held on 10-13 October 2016 in Chengdu, China. The 15th ISGdR is to be held at the Shimane University in Matsue, Japan from 26 to 31 August 2017. This article firstly outlines the background and aims of the ISGdR, reports on the 14th ISGdR in Chengdu, China, and then announces the plans for the 15th ISGdR in Matsue, Japan. Finally, it acknowledges for contributions for the organization of the 14th ISGdR.
\end{abstract}

Keywords: International Consortium on Geo-disaster Reduction (ICGdR), International Symposium on Geo-disaster Reduction (ISGdR), Southwest Jiaotong University (SWJTU)

\section{Introduction}

\section{Background of the ICGdR and ISGdR}

The International Consortium on Geo-disaster Reduction (ICGdR) is an international non-governmental and non-profit scientific organization legally registered as a non-profit organization in 2013 in the Shimane Prefecture according to the Japanese law (Wang 2014). Before the official establishment of the ICGdR, the core members had conducted preparatory activities for 10 years. In 2003, the first symposium was held at Kanazawa University, Japan for the mitigation of geo-disasters in the areas around Japan Sea, which drew attention of researchers and engineers from China, Korea and Japan. The second, third and fourth symposiums were also held at Kanazawa University. Then, the fifth and sixth symposiums were held at Chang'an University and Kunming University of Science and Technology in China, respectively. In 2009, the symposium was renamed as "The International Symposium on Mitigation of Geo-disasters in Asia" in order to include more countries and to cover a larger area. The seventh event was then held in Northeast Forestry University, China. The eighth and ninth symposiums were held in National Far-East Technology University, Vladivostok,

\footnotetext{
* Correspondence: chengqiangong@home.swjtu.edu.cn

'Department of Geological Engineering, Southwest Jiaotong University,

Chengdu, Sichuan 610031, China

Full list of author information is available at the end of the article
}

Russia in 2010, and Universitas Gadjah Mada, Yogyakarta, Indonesia in 2011, respectively. Gradually, the event transformed from regional to international. In 2012, Shimane University, Japan organized the 10th symposium, and about 100 participants attended this event. According to a regional initiative from Asia, the participants, of which most are experts on geo-disaster reductions, had intent to establish an international consortium on geo-disaster reduction. In May 2013, the organizing meeting of the International Consortium on Geo-disaster Reduction (ICGdR) was held in China Institute of Disaster Prevention, Beijing, China. And later, the legal registration was completed in August 2013 in Matsue, Japan.

In 2013, the 11th symposium was successfully held in Kathmandu, Nepal. The Nepalese Prime Minister (the Chairman of the Interim Council of Ministers) inaugurated this event and gave great concern to geo-disaster reduction in the region. Based on the success of the last ten symposia, the core members of ICGdR have agreed to open the symposium to now include the whole world, as well as Asia. At this time the symposium was officially renamed the "International Symposium on Geo-disaster Reduction (ISGdR)". The 12th and 13th ISGdR was held in Fullerton, California, USA in 2014 and in Prague, Czech Republic in 2015, respectively. 


\section{Objectives of the ICGdR and ISGdR}

1. Promote geo-disaster reduction for the benefit of human society and the natural environment, and capacity development, including education;

2. Combine international expertise and coordinate their efforts in geo-disaster reduction, thereby resulting in an effective international organization which will act as a partner in various projects;

3. Promote regional and global, multidisciplinary activity on geo-disaster reduction.

\section{Organizers and organizing committee of the 14th ISGdR}

Organizers: State-province Joint Engineering Laboratory of Spatial Information Technology for High Speed Railway Safety (Southwest Jiaotong University, China) and International Consortium on Geo-disaster Reduction (ICGdR).

In cooperation with: State Key Laboratory of Geohazard Prevention and Geoenvironment Protection, (Chengdu University of Technology, China), Key Laboratory of Mountain Hazards and Earth Surface Processes (Institute of Mountain Hazards and Environment, Chinese Academy of Sciences), State Key Laboratory of Hydraulic and Mountain River Engineering (Sichuan University, China), State Key Laboratory of Frozen Soil Engineering (Cold and Arid Regions Environmental and Engineering Research Institute, Chinese Academy of Sciences), Kunming University of Science and Technology (China), and National Natural Science Foundation of China.

Organizing committee: Chair Person: Fei Xu (President, Southwest Jiaotong University, China).

Vice Chair Persons: Heming Cheng (Vice President, Kunming University of Science and Technology, China), Wei Deng (Director, Institute of Mountain Hazards and Environment, Chinese Academy of Sciences), Wei Ma (Director, Cold and Arid Regions Environmental and Engineering Research Institute, Chinese Academy of Sciences), Qiang Xu (Executive Vice Director, State Key Laboratory of Geohazard Prevention and Geoenvironment
Protection, Chengdu University of Technology, China), Weiling Xu (Vice President, Sichuan University, China), Fawu Wang (Director-General, International Consortium on Geo-disaster Reduction), Wengui Zhang (Vice President, Southwest Jiaotong University, China).

Committee Members: Xiaoqing Chen, Ranjan Kumar Dahal, Chuan He, Xiewen Hu, Huijun Jin, Bo Li, Tianbin Li, Guoxiang Liu, Xinnian Liu, Yu Liu, Fujun Niu, Shengwen Qi, Ruitang Xu, Juhua Xiong, Yupeng Yao, Qing Zhu.

Secretariat: Chair Person: Qiangong Cheng.

Vice Chair Persons: Hongbo Cai, Guangzhu Cao, Wei Che, Wei Hu, Guoyu Li, Shiguo Xiao, Lu Zheng, Gongdan Zhou.

Members: Tao Chen, Zili Dai, Xuanmei Fan, Fang Guan, Lanxin Huang, Fang Lin, Zhanju Lin, Chaojun Ouyang, Ronggao Qin, Yufeng Wang, Duqiang Yang, Hufeng Yang.

\section{Report of the 14th ISGdR}

State-province Joint Engineering Laboratory of Spatial Information Technology for High Speed Railway Safety, Southwest Jiaotong University organized the 14th International Symposium on Geo-Disaster Reduction (ISGdR) in Chengdu, China on 10-13 October 2016 (Fig. 1). This series of international symposiums has been an instrumental forum for the "Global Strategy for Geo-disaster Reduction" which attracted more than one hundred geoscientists and engineers working in the field of geo-disasters from six countries and 63 excellent academic presentations. The symposium has been divided into four major sections: High Level Forum, Keynote Lectures, Invited Lectures and Young Researcher Forum, offering an opportunity to discuss the latest developments in the field of Geo-disaster Reduction. In addition to the main sessions of the symposium, pre-event, side-events and post-event were also organized before, during and after the symposium.

\section{Pre-event}

The 2016 General Meeting of ICGdR took place at the Xinhua Hotel on 10 October 2016. Prof. Miyajima, the

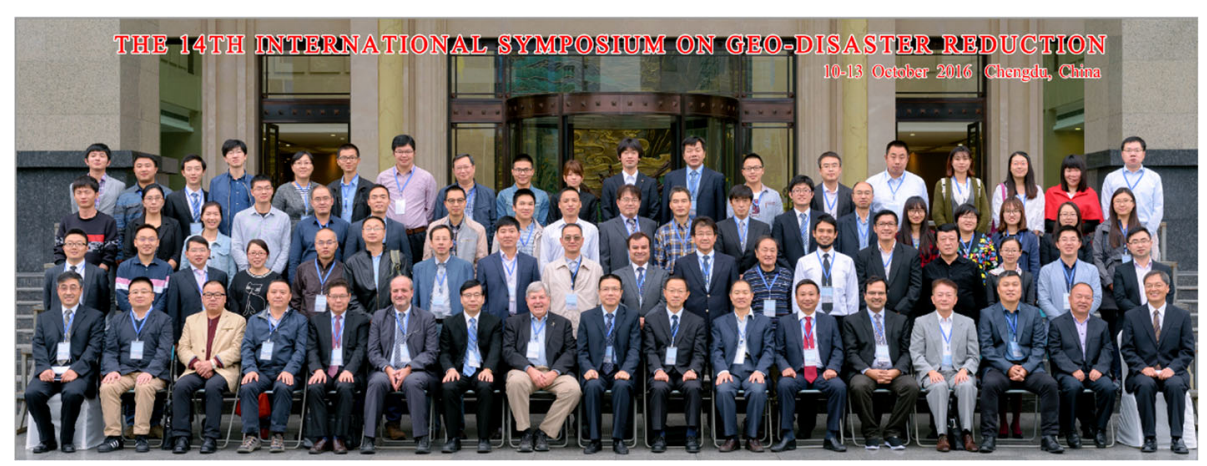

Fig. 1 Group photo of participants of the 14th ISGdR 
president of ICGdR, delivered an opening address. During the meeting, current membership, financial condition and annual report of each committee (Annual Symposium Committee, Training Course Committee, Journal Editorial Committee, Project Collaboration Committee, Database Committee and Award Committee) for 2016 were reported by each responsible person. The working plan for 2017 was discussed at the end of the general meeting. Prof. Xuanmei Fan, from the State Key Laboratory of Geohazard Prevention and Geoenvironment Protection (Chengdu University of Technology, China), was elected as the director of Young Researcher Committee of ICGdR. Shimane University (Japan) was voted as the organizer of the 15th ISGdR, and the symposium will be held on 26-31 August 2017.

\section{Plenary sessions of the symposium Opening ceremony}

The opening ceremony was hosted by Prof. Fawu Wang, the Director-General of ICGdR (Fig. 2). Prof. Fei Xu has declared the conference open on behalf of the organizer, Southwest Jiaotong University (SWJTU), and delivered an opening speech to welcome all the distinguished scholars and experts from all over the world. Prof. Fei $\mathrm{Xu}$ also expressed his hope that this symposium could provide a platform for researches to forefront research into the mechanism of geological hazards and promote the further development of disaster prevention and mitigation technology. Prof. Masakatsu Miyajima, the president of ICGdR, and Dr. Sheng Xian, the associated director of Disaster Mitigation Center of Sichuan Province, also delivered greeting speeches to welcome all the researchers and their appreciation to organizers.

\section{Award ceremony}

Prof. Masakatsu Miyajima and Prof. Fei Xu presented awards and certificates to recipients (Fig. 3). These awards included the 2015 Outstanding Events, 2015 Outstanding ICGdR Member of the Year and 2015 Outstanding Paper. Due to the absence of Prof. Vit Vilimek, his award ceremony is not shown in Fig. 3. The awards details are list in Table 1.

\section{High level forum}

The High Level Forum was chaired by Prof. Fawu Wang. Five famous experts delivered their plenary lectures focusing on the theme of "Global Strategy for Geo-disaster Reduction" (Fig. 4): "Importance of communicating natural hazards to the public - an Oregon, USA example" by Prof. Scott Burns (President of IAEG), "Disaster risk reduction in one belt one road area" by Prof. Peng Cui (Academician, Chinese Academy of Sciences), "Study on control theory of landslide based on the evolution process" by Prof. Huiming Tang (Vice President, China University of Geosciences, Wuhan, China), "New technologies for landslide monitoring and rapid mapping" by Prof. Nicola Casagli (Deputy Director of UNESCO Chair on the Prevention \& Sustainable management of GeoHydrological Hazards, University of Florence, Italy), "Lessons learned from recent damaging earthquakes in Taiwan, Japan and Italy" by Prof. Masakatsu Miyajima (Kanazawa University, President of ICGdR).

\section{Keynote lectures}

The Keynote Lectures included 8 plenary lectures which were divided into two sections. The first section was chaired by Prof. Masakatsu Miyajima and Prof. Qiangong

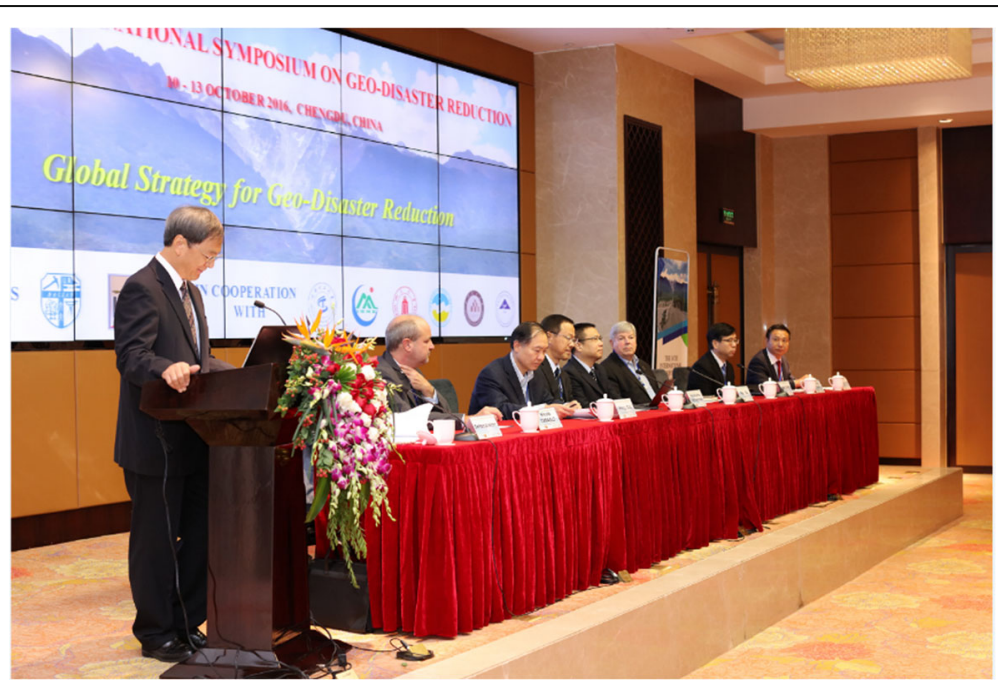

Fig. 2 Prof. Fawu Wang hosted the opening ceremony of the 14th ISGdR 

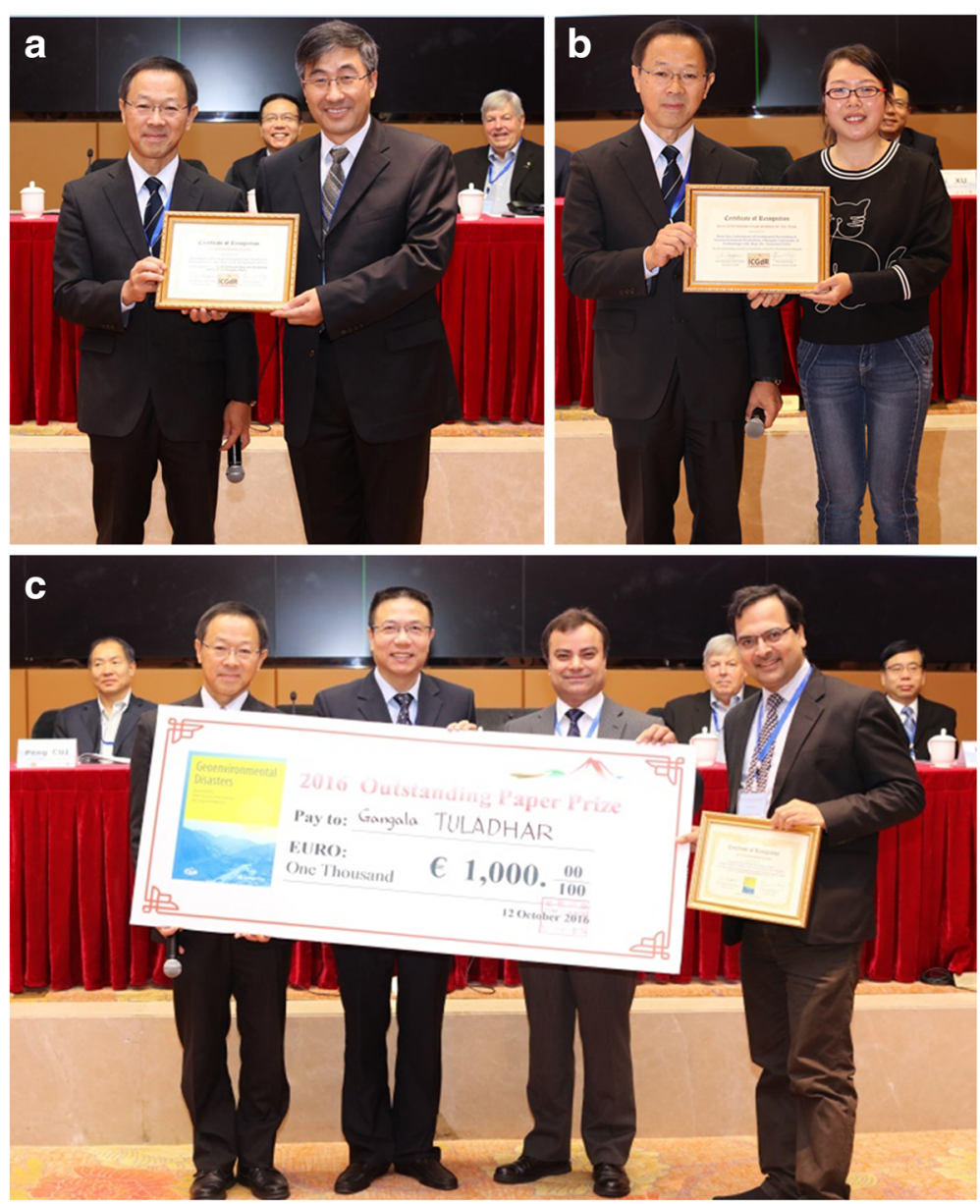

Fig. 3 Prof. Qiangong Cheng (a) and Prof. Xuanmei Fan (b) received the certificates from Prof. Masakatsu Miyajima. Dr. Ranjan Kumar Dahal and Dr. Netra Prakash Bhandary (c) received the certificate from Prof. Fei Xu

Cheng. Firstly, Prof. Fawu Wang presented their research on landslide dam to predict the failure time through indoor and out-door landslide dam model tests and field investigation. The second keynote lecture from Prof. Guoxiang Liu concentrated on a case study for mapping and inventorying active rock glaciers in the Northern Tien Shan (China) by InSAR. Prof. Qiang Xu introduced their study on diffuse failure landslides including a landfill flow-slide, some loess landslides and a landslide of loose deposits, and attempted to assess the initiation of diffuse

Table 1 Lists of awards for the 14th ISGdR

\begin{tabular}{|c|c|c|c|}
\hline Title & Affiliation & Contributions & Representative \\
\hline 2015 Outstanding Events & $\begin{array}{l}\text { Department of Physical Geography } \\
\text { and Geoecology, Faculty of Science, } \\
\text { Charles University in Prague }\end{array}$ & $\begin{array}{l}\text { For the contribution to the 13th International } \\
\text { Symposium on Geodisaster Reduction in } \\
\text { Prague, Czech Republic }\end{array}$ & Vit Vilimek \\
\hline 2015 Outstanding Events & $\begin{array}{l}\text { Department of Geological Engineering, } \\
\text { Southwest Jiaotong University }\end{array}$ & $\begin{array}{l}\text { For the contribution of the Working Meeting } \\
\text { and Workshop of ICGdR in Chengdu, China }\end{array}$ & Qiangong Cheng \\
\hline $\begin{array}{l}2015 \text { Outstanding ICGdR } \\
\text { Member of the Year }\end{array}$ & $\begin{array}{l}\text { State Key Laboratory of Geohazard } \\
\text { Prevention and Geoenvironment } \\
\text { Protection, Chengdu University of } \\
\text { Technology }\end{array}$ & $\begin{array}{l}\text { For the outstanding research on landslides } \\
\text { induced by Wenchuan Earthquake }\end{array}$ & Xuanmei Fan \\
\hline 2015 Outstanding Paper & $\begin{array}{l}\text { Himalaya Conservation Group, Ehime } \\
\text { University, Tribhuvan University }\end{array}$ & $\begin{array}{l}\text { For the paper "Disaster risk reduction } \\
\text { knowledge of local people in Nepal" }\end{array}$ & $\begin{array}{l}\text { Gangalal Tuladhar } \\
\text { Ryuichi Yatabe } \\
\text { Ranjan Kumar Dahal } \\
\text { Netra Prakash Bhandary }\end{array}$ \\
\hline
\end{tabular}



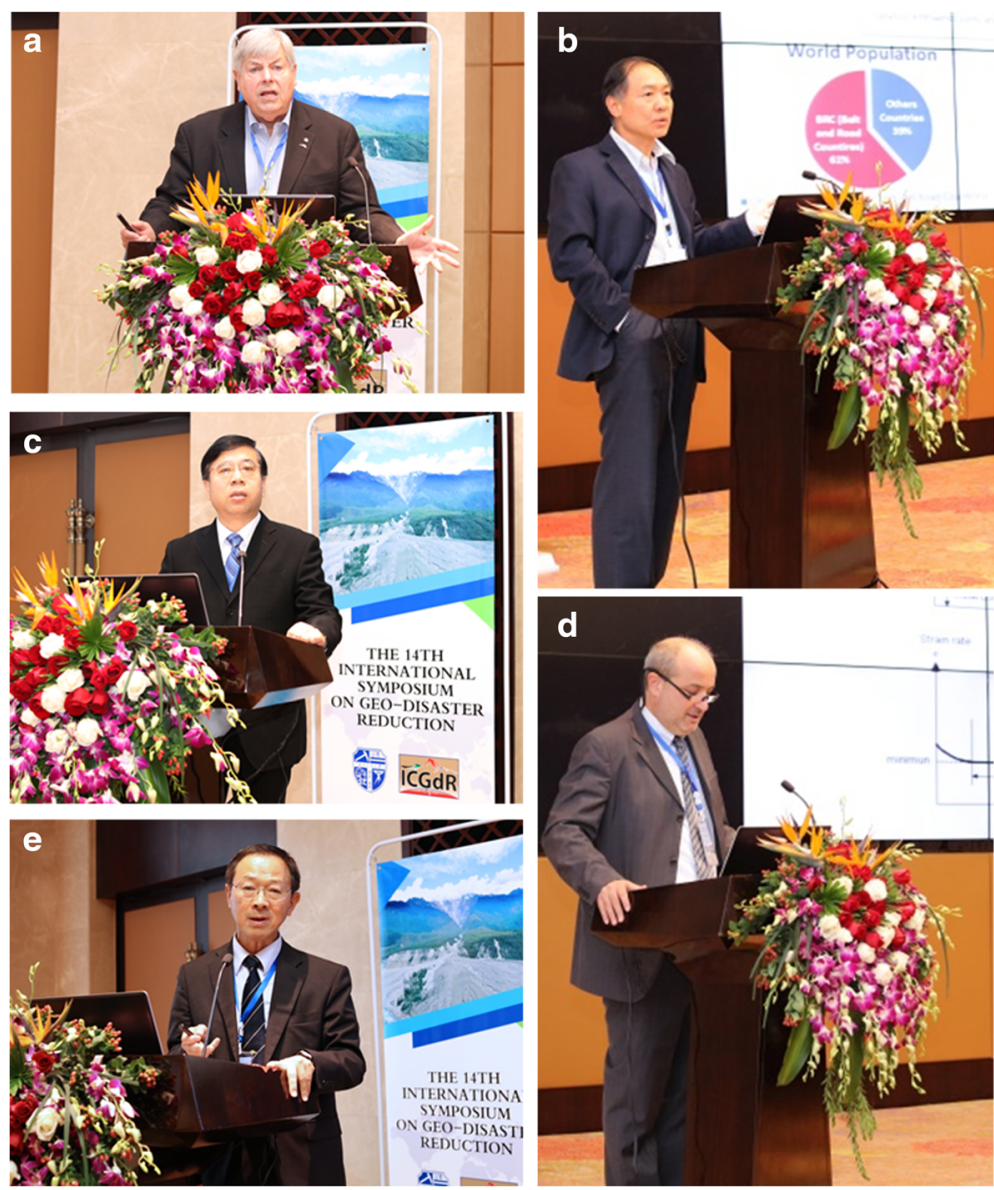

Fig. 4 Plenary lectures presented by Prof. Scott Burns (a), Prof. Peng Cui (b), Prof. Huiming Tang (c), Prof. Nicola Casagli (d) and Prof. Masakatsu Miyajima (e) during the High Level Forum

failure landslides. At the end of first section, Prof. Hengxing Lan gave a lecture on geo-hazards risk assessment for Sichuan-Tibet interconnection project of state grid based on the engineering geological conditions, regional geological condition, geological hazards investigation, project design, the remote sensing interpretation and numerical modelling.

The second section of Keynote Lectures was chaired by Prof. Huiming Tang and Prof. Nicola Casagli. Prof. Xianzhang Ling's lecture highlighted two important research topics on vibration response of railway traffic subgrade and vibration response of road traffic subgrade with heavy load in cold regions. Furthermore, the finished fundamental work on above-mentioned topic was discussed and elaborated. Prof. Yu Huang presented research on the flow slides in MSW landfills and provided a scientific basis for hazard prevention and risk evaluation in the landfill area. Two kinds of mesh free method, a smoothed particle hydrodynamics (SPH) model, and a modified moving particle semi-implicit (MPS) model were proposed to predict the propagation of the flow slides in MSW landfill in two dimensional and three dimensional. Prof. Ranjan Kumar Dahal introduced major geological and geomorphological issues in central Nepal after the Gorkha Earthquake and conducted detail analysis to understand liquefaction problem, landslide problem and topographic and basin effect. At the end of Keynote Lecture, Prof. Guangqi Chen proposed a practical 3D coupled solid-fluid simulation technique by using DDA and SPH to analyze the formation and failure characteristics of the landslide dam. The developed simulation technique has been successfully applied to simulate a practical landslide dam and its effectiveness and practicality have also been validated.

The titles of presentations of Keynote Lectures are list in Table 2. Figure 5 shows photos of each presenter during Keynote Lectures.

\section{Poster session}

The poster session was held at the plenary meeting hall. The authors of four posters took part in the discussion and exchange views with other participants during the 
Table 2 Lists of Keynote Lectures

\begin{tabular}{llll}
\hline No. & Title & Presenter & Affiliation \\
\hline K-1 & Prediction of landslide dam failure by piping & Fawu Wang & Shimane University \\
K-2 & Mapping and inventorying active rock glaciers in the Northern Tien Shan (China) & Guoxiang Liu & Southwest Jiaotong University \\
K-3 & Study on mechanism of diffuse failure landslides & Qiang Xu & Chengdu University of Technology \\
K-4 & Geo-hazards risk assessment for Sichuan-Tibet interconnection project of state grid & Hengxing & Chinese Acade my of Sciences \\
& Lan & \\
K-5 & Vibration analysis of traffic subgrade in cold regions & Xianzhang & Harbin Institute of Technology Qingdao \\
K-6 & On the flow slides in municipal solid waste landfills & Ling & University of Technology \\
K-7 & Geology and geomorphology related damages and their consequences after the & Yu Huang & Tongji University \\
2015 Gorkha Earthquake in central Nepal & Tribhuvan University \\
K-8 & $\begin{array}{l}\text { Development of a 3D coupled solid-fluid simulation technique using DDA and SPH Hahal } \\
\text { for analysis of landslide induced chain disasters }\end{array}$ & $\begin{array}{l}\text { Guangqi } \\
\text { Chen }\end{array}$ & Kyushu University \\
\hline
\end{tabular}
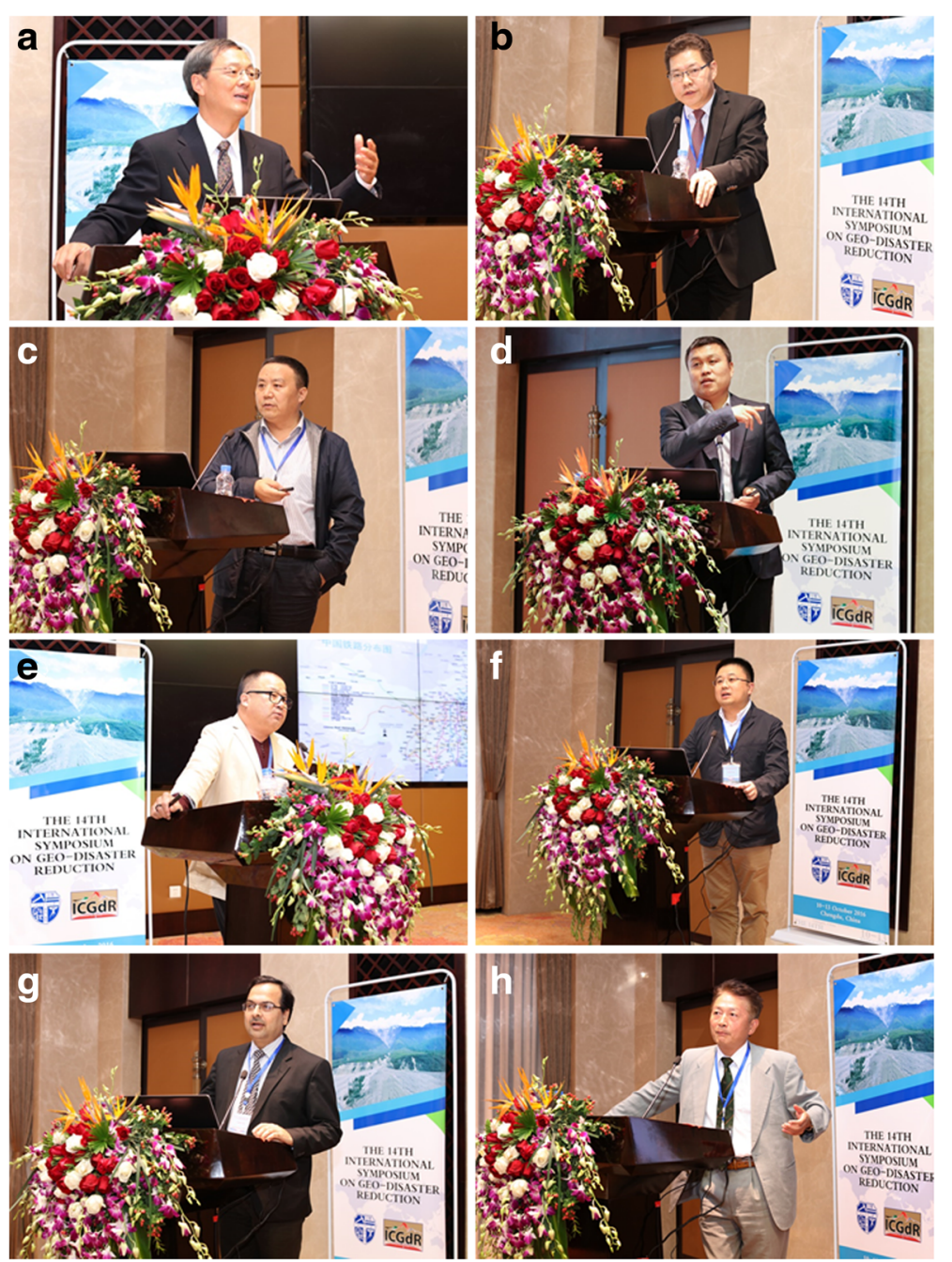

Fig. 5 Plenary lectures presented by Prof. Fawu Wang (a), Prof. Guoxiang Liu (b), Prof. Qiang Xu (c), Prof. Hengxing Lan (d), Prof. Xianzhang Ling (e), Prof. Yu Huang (f), Prof. Ranjan Kumar Dahal (g) and Prof. Guangqi Chen (h) during the Keynote Lectures 
Table 3 Lists of Poster Session

\begin{tabular}{llll}
\hline No. & Title & Presenter & Affiliation \\
\hline P-1 & $\begin{array}{l}\text { Experimental studies on quality evaluation of a liquefaction-countermeasure } \\
\text { construction method by desaturation with two types of air bubble }\end{array}$ & Hiroshi Nakazawa & $\begin{array}{l}\text { National Research Institute for Earth Science } \\
\text { and Disaster Resilience, Japan }\end{array}$ \\
P-2 & Damage survey on gabion structures in the $2015 \mathrm{Nepal}$ Gorkha earthquake \\
P-3 & $\begin{array}{l}\text { Thermal regimes of permafrost along the Qinghai-Tibet Railway under } \\
\text { climate warming }\end{array}$ & $\begin{array}{l}\text { Kentaro Kuribayashi } \\
\text { Xiaoyun Su }\end{array}$ & $\begin{array}{l}\text { Eight-Japan Engineering Consultants Inc. } \\
\text { China Earthquake Administration }\end{array}$ \\
P-4 $\begin{array}{l}\text { Development of global disaster prevention and mitigation think tanks } \\
\text { and suggestions for Chinese new disaster mitigation think tanks construction }\end{array}$ & Wanjing Ji & China Earthquake Administration \\
\hline
\end{tabular}

tea and lunch break time on 11 October. The details of poster session are listed in Table 3 .

\section{Parallel sessions}

The Parallel Sessions included Invited Lectures and Young Researcher Forum. Totally, there were 50 presentations. The topics are related to landslides, geo-disasters caused by earthquake, social resilience to disasters and new technologies for geo-disaster reduction. The details of presentations are listed in Tables 4 and 5.

\section{Side-events}

Chengdu is a historical city and famous for the giant pandas in the world. During the symposium, two side-

Table 4 Lists of lectures presented in Invited Lectures

\begin{tabular}{|c|c|c|c|}
\hline No. & Title & Presenter & Affiliation \\
\hline $1-1$ & Soil moisture migration and slope failure in the loess region & Tonglu Li & Chang'an University \\
\hline $1-2$ & $\begin{array}{l}\text { Cascade densely distributed large landslide dams on the mainstream of upper } \\
\text { Jinsha River }\end{array}$ & Fuchu Dai & Beijing University of Technology \\
\hline $1-3$ & $\begin{array}{l}\text { Residual-state shear creep in clayey soils and its modeling for large-scale } \\
\text { landslide failure prediction }\end{array}$ & Netra Prakash Bhandary & Ehime University \\
\hline $1-4$ & Study on countermeasure against liquefaction by piling logs with drainage function & Masaho Yoshida & National Institute of Technology \\
\hline $1-5$ & Initiation mechanism and seismic precursor of fluidized landslide in loose soil & Wei Hu & Chengdu University of Technology \\
\hline $1-6$ & The new progress of landslide mapping and risk assessment of CGS & Jusong Shi & China Geological Survey \\
\hline $1-7$ & $\begin{array}{l}\text { Effects of lattice-shaped wall and drains against liquefaction of grounds } \\
\text { evaluated by three dimensional dynamic effective stress analysis }\end{array}$ & Fei Cai & Gunma University \\
\hline $1-8$ & Behavior of dip bedded rock slope under shaking table test & Shengwen Qi & Chinese Academy of Sciences \\
\hline $1-9$ & Numerical simulation and limit analysis of slopes under complex circumstance & Tingkai Nian & Dalian University of Technology \\
\hline $1-10$ & $\begin{array}{l}\text { Seismic performance of masonry wall based on shaking table test and large } \\
\text { deformation analysis }\end{array}$ & Toshikazu Ikemoto & Kanazawa University \\
\hline $\mid-11$ & Physical model and simulation of dynamic evolution of mountain hazard & Siming He & Chinese Academy of Science \\
\hline $1-12$ & $\begin{array}{l}\text { Development of thermokarst related-hazards in permafrost regions of the } \\
\text { Qinghai-Tibet Plateau }\end{array}$ & Fujun Niu & Chinese Academy of Science \\
\hline $1-13$ & Dynamic analysis of several rock avalanches in Southwestern China & Aiguo Xing & Shanghai Jiao Tong University \\
\hline $1-14$ & $\begin{array}{l}\text { Landslides caused by climate change and groundwater movement in } \\
\text { permafrost mountain }\end{array}$ & Wei Shan & Northeast Forestry University \\
\hline $\mid-15$ & Effects of seismic loading on the run-out of rockfall & Yingbin Zhang & Southwest Jiaotong University \\
\hline $\mid-16$ & $\begin{array}{l}\text { Late Quaternary slipping rates and paleo-earthquakes of Xiadian Fault in } \\
\text { Beijing Plain area }\end{array}$ & Jun Shen & Institute of Disaster Prevention \\
\hline $1-17$ & $\begin{array}{l}\text { Developing a high-performance hydro-geohazards modelling tool to support } \\
\text { catchment systems management }\end{array}$ & Qiuhua Liang & Newcastle University \\
\hline $\mid-18$ & Hazard study on impulsive wave-induced by landslides in Three Gorges Reservoir & Bolin Huang & China Geological Survey \\
\hline $1-19$ & $\begin{array}{l}\text { Mechanisms of particle segregation in granular debris flows and their effect } \\
\text { on the flowing mobility }\end{array}$ & Gongdan Zhou & Chinese Academy of Sciences \\
\hline $1-20$ & $\begin{array}{l}\text { Reinforcement effect analysis of stabilizing piles with isosceles trapezoid } \\
\text { cross-section on the landslides }\end{array}$ & Changdong Li & $\begin{array}{l}\text { China University of Geosciences } \\
\text { (Wuhan) }\end{array}$ \\
\hline
\end{tabular}


Table 5 Lists of lectures presented in Young Researcher Forum

\begin{tabular}{|c|c|c|c|}
\hline No. & Title & Presenter & Affiliation \\
\hline $\mathrm{Y}-1$ & $\begin{array}{l}\text { Soil mass failure due to water infiltration and sub-erosion: a case study of the soil } \\
\text { slope failure at the national geological park of Qian-an mud forest, China }\end{array}$ & Yan Xu & Jilin University \\
\hline $\mathrm{Y}-2$ & Landslides in loess plateaus: distribution, characteristics and formations & Jianqi Zhuang & Chang'an University \\
\hline Y-3 & $\begin{array}{l}\text { Initiation mechanism of heavy rainfall-induced shallow landslides on steep slopes } \\
\text { with impermeable bedrock }\end{array}$ & Hufeng Yang & Southwest Jiaotong University \\
\hline $\mathrm{Y}-4$ & Liquefaction caused by the 2016 Kumamoto Earthquakes in Japan & Hendra Setiawan & Kanazawa University \\
\hline Y-5 & Particle breakage and the critical state of sand & Fangwei Yu & Chinese Academy of Sciences \\
\hline Y-6 & $\begin{array}{l}\text { Weathering zonation characteristics of paleo-weathering crust of red bed } \\
\text { mudstone in Heifangtai Area }\end{array}$ & Yutian Ke & Lanzhou University \\
\hline Y-7 & $\begin{array}{l}\text { Geotechnical investigation and numerical analysis of rockfall in south coast of } \\
\text { Gunung Kidul Regency, Yogyakarta Province, Indonesia }\end{array}$ & Fikri Faris & Universitas Gadjah Mada \\
\hline Y-8 & $\begin{array}{l}\text { The disaster chain effect of the geological hazards associated with the Wenchuan } \\
\text { earthquake }\end{array}$ & Xuanmei Fan & $\begin{array}{l}\text { Chengdu University of } \\
\text { Technology }\end{array}$ \\
\hline Y-9 & $\begin{array}{l}\text { Random trials method used in determining the critical yield acceleration coefficient } \\
\text { for three-dimensional slopes with reinforcement }\end{array}$ & Yi He & Southwest Jiaotong University \\
\hline Y-10 & $\begin{array}{l}\text { Damage to water supply system by geo-disasters in the } 2016 \text { Kumamoto Earthquake } \\
\text { in Japan }\end{array}$ & $\begin{array}{l}\text { Mitsuru } \\
\text { Nakamura }\end{array}$ & Kanazawa University \\
\hline$Y-11$ & Testing rock fragmentation on various slopes via 3D DEM modeling & Tao Zhao & Sichuan University \\
\hline$Y-12$ & $\begin{array}{l}\text { Damage to houses and buildings induced by liquefaction in the } 2016 \text { Kumamoto } \\
\text { Earthquakes In Japan }\end{array}$ & Yuko Serikawa & Kanazawa University \\
\hline$Y-13$ & Numerical simulation of direct shearing test for unsaturated soil at microscopic scale & Longxiao Guo & Chang'an University \\
\hline Y-14 & A new method for estimating Vs30 of a site based on the fundamental period & Wenhao Qi & $\begin{array}{l}\text { Institute of Engineering } \\
\text { Mechanics, CEA }\end{array}$ \\
\hline Y-15 & The effect of undisturbed $Q_{3}$ loess's microstructure on its SWCC & Xiaokun Hou & Chang'an University \\
\hline Y-16 & $\begin{array}{l}\text { Estimation of strong motion using } \mathrm{H} / \mathrm{N} \text { spectral ratio of microtremor observation } \\
\text { during resent earthquake in Japan }\end{array}$ & Akira Murata & Kanazawa University \\
\hline Y-17 & Influences of material constituent in the mobility of rock-ice avalanches & Qingqing Yang & Southwest Jiaotong University \\
\hline Y-18 & Moisture migration in the unsaturated loess under the natural environment & YuXi & Chang'an University \\
\hline Y-19 & Experimental study on the mechanical behaviors of large rock avalanche basal facie & Yufeng Wang & Southwest Jiaotong University \\
\hline Y-20 & Research on the constitutive model of unsaturated loess & Xinting Zhang & Chang'an University \\
\hline Y-21 & Model test on impact behaviour of submarine landslides on undersea cables & Zili Dai & Shimane University \\
\hline $\mathrm{Y}-22$ & The mechanism of irrigation-induced loess landslide & Xianli Xing & $\begin{array}{l}\text { Taiyuan University of } \\
\text { Technology }\end{array}$ \\
\hline Y-23 & Simulation of debris flows around bridge piers & Wei Liu & Chinese Academy of Sciences \\
\hline Y-24 & Simulation of mock-up tests on GMZ bentonite with double structure models & Langjing Shi & Tongji University \\
\hline Y-25 & $\begin{array}{l}\text { Numerical simulation for the dynamic process of rainfall-induced debris flow in the } \\
\text { small mountainous watershed }\end{array}$ & Jiawen Zhou & Sichuan University \\
\hline Y-26 & Search for sliding surface of slope based on DSRM & Guoqing Chen & $\begin{array}{l}\text { Chengdu University of } \\
\text { Technology }\end{array}$ \\
\hline Y-27 & $\begin{array}{l}\text { Resolving frictional contact problems in three-dimensional discontinuous } \\
\text { deformation analysis and its application in landslide simulation }\end{array}$ & Lu Zheng & Sichuan University \\
\hline $\mathrm{Y}-28$ & $\begin{array}{l}\text { Deformation of landslide triggered by water level fluctuation: a case study } \\
\text { on Shuping landslide in the Three Gorges Reservoir, China }\end{array}$ & Kun Song & China Three Gorges University \\
\hline Y-29 & $\begin{array}{l}\text { A unified mathematical framework for modelling gravity-driven water } \\
\text { and mass flows }\end{array}$ & Xilin Xia & Newcastle University \\
\hline Y-30 & Motive modes of the landslides on the Chinese Loess Plateau & Wei Shen & Chang'an University \\
\hline
\end{tabular}




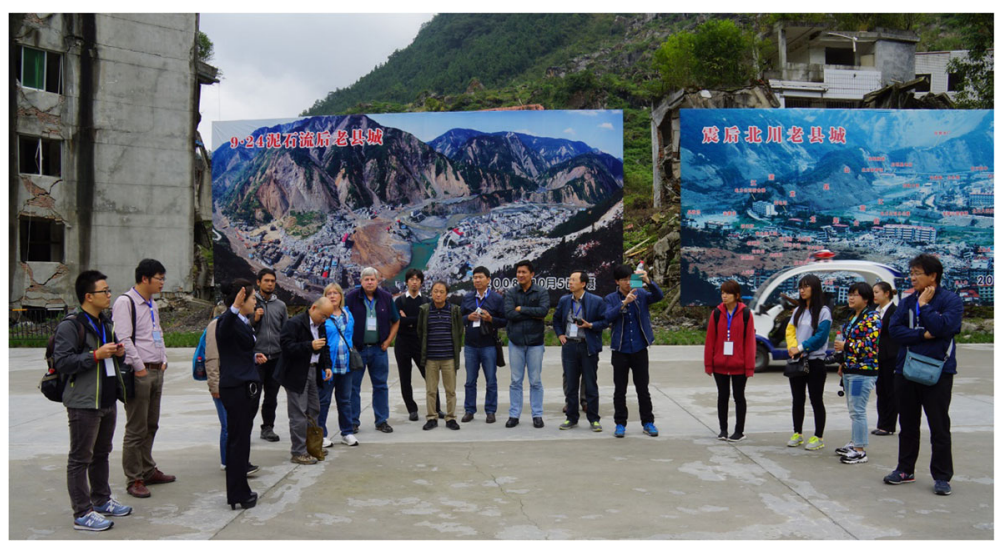

Fig. 6 Prof. Wei Hu introduced the situation of Old Beichuan County before and after earthquake

events, Giant Panda Base Visiting and Sichuan Art Performance, were organized for participants, especially for foreigners. It was a good opportunity for them to take a close contact with Chinese culture.

\section{Closing session}

Prof. Fawu Wang, on behalf of ICGdR, gave a closing speech and appreciation to the organizer and co-organizers. At the end, Prof. Masakatsu Miyajima and Prof. Scott Burns presented awards of "Outstanding Young Researcher Forum" to the recipients from the Young Researcher Forum

\section{Post-event}

With the contribution of State Key Laboratory of Geohazard Prevention and Geoenvironment Protection
(Chengdu University of Technology, China), 19 participants joined the field trip to Old Beichuan County after 2008.5.12 Wenchuan Earthquake. During the field trip, Prof. Wei $\mathrm{Hu}$ introduced the situation of Old Beichuan County before and after 2008.5.12 Wenchuan Earthquake (Fig. 6). At the location of earthquake fault, an in-situ discussion was conducted to have more knowledge about earthquake based on landform and vegetation (Fig. 7).

\section{Invitation}

The 15th ISGdR will be held on 26-31 August 2017 in Matsue City, Shimane Prefecture, Japan. The ICGdR will invite all entities and individuals which are willing to contribute to the geo-disaster reduction to join ICGdR.

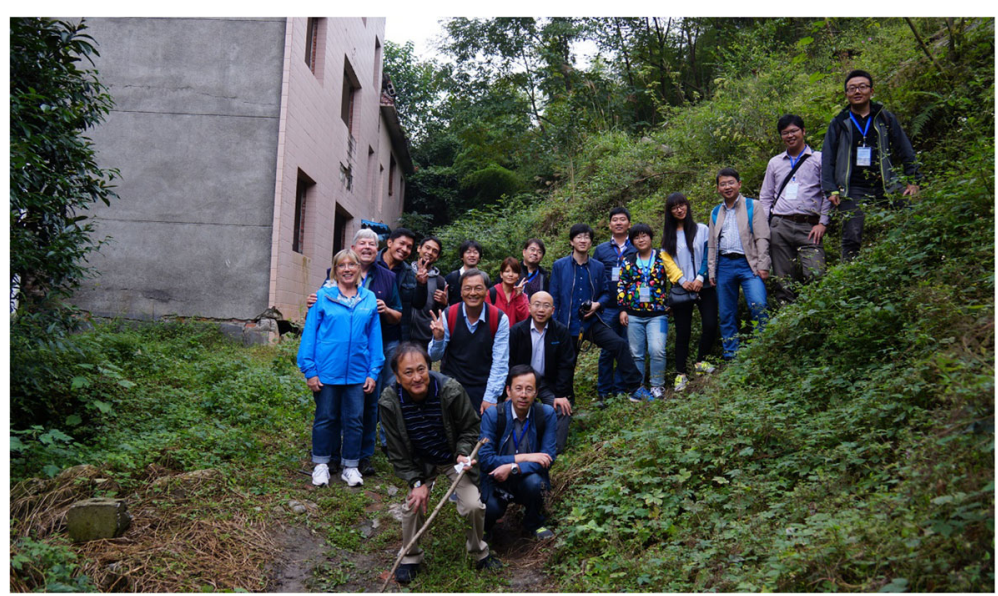

Fig. 7 Group photo at the location of earthquake fault 


\section{Acknowledgements}

The organization of the 14th ISGdR was strongly supported by all joint organizers and cosponsors in many aspects. Thanks for financial support go to the State-province Joint Engineering Laboratory of Spatial Information Technology for High Speed Railway Safety (Southwest Jiaotong University, China), Key Laboratory of Mountain Hazards and Earth Surface Processes (Institute of Mountain Hazards and Environment, Chinese Academy of Sciences), and State Key Laboratory of Frozen Soil Engineering (Cold and Arid Regions Environmental and Engineering Research Institute, Chinese Academy of Sciences). Also, we extend our sincere thanks to State Key Laboratory of Geohazard Prevention and Geoenvironment Protection (Chengdu University of Technology, China) for their contribution to the field trip to Old Beichuan County after the 2008.5.12 Wenchuan Earthquake.

\section{Author details}

'Department of Geological Engineering, Southwest Jiaotong University, Chengdu, Sichuan 610031, China. ${ }^{2}$ Department of Geoscience, Shimane University, Matsue, Shimane 690-8504, Japan.

Received: 6 December 2016 Accepted: 6 December 2016

Published online: 04 January 2017

\section{Reference}

Wang, F. 2014. Reducing geo-disasters for improving the relationships between geoenvironment and society. Geoenvironmental Disasters 1(1): 1-3.

\section{Submit your manuscript to a SpringerOpen ${ }^{\circ}$ journal and benefit from:}

- Convenient online submission

- Rigorous peer review

- Immediate publication on acceptance

- Open access: articles freely available online

- High visibility within the field

- Retaining the copyright to your article

Submit your next manuscript at $\gg$ springeropen.com 